\title{
Police violence flares up at Russian education protest
}

[MOSCOW] Police in Ekaterinburg, the capital of the Sverdlovsk district in the Urals and home of the Russian president, Boris Yeltsin, last week attacked students from local universities who had taken part in a national protest against proposed educational reforms (see Nature 392, 429; 1998).

Between 3,000 and 4,000 students gathered at the city's Youth Palace for a meeting that had been approved by the city council. After discussing their problems and the apparent indifference of federal and local authorities to their needs, they adopted a resolution demanding that the president and the cabinet abandon reforms that, they argue, would make higher education unaffordable for most people.

The leaders of the students' trade-union association, which organized the meeting, then asked the students to return home. But more than 1,500 students, angry that no member of the city authorities had agreed to meet them, moved to the Ekaterinburg city council.

They then marched to the Sverdlovsk district administration, where 200 students approached the main entrance of the district government's building. Some were eventually admitted, and met Anatoly Gaida, the first deputy head of the district government, responsible for education, science and culture, who endorsed the students' demands and added some of his own.

Meanwhile, more than 250 members of the Special Police Force, armed with steel shields and rubber clubs and accompanied by a military armoured car, started to move the students out of the government building. Injuries were received by many students.

Local television reports, subsequently shown nationwide, generated wide indignation. Yeltsin ordered the newly appointed acting minister of internal affairs, Sergei Stepashin, to investigate the case urgently, and the parliament also set up a special commission of inquiry.

Sergei Kirienko, the acting prime minister, said the cabinet was deeply concerned by the incident. General Boris Gromov, a former head of Russian troops in Afghanistan, said that "only silly and irresponsible people could throw at our future with police clubs".

Yuri Brusnitsin, the president's recently appointed representative in the Sverdlovsk district, promised to pass on the students' demands to Yeltsin. The students told him that, although they were until recently "passive politically", that did not mean their needs "should be neglected by the authorities".

University lecturers from Ekaterinburg who attended the student meeting told local officials that, although they had previously acted as a "separating layer" between the authorities and the young people, they would join the students "if the present educational policy is kept unchanged".

Three high-ranking officials of the Sverdlovsk district government, including Gaida, have already been dismissed. The heads of the district and city police forces, who ordered the use of the special forces, are also likely to lose their jobs.

CarlLevitin

\section{Heed public opinion, British geologists told}

[LONDON] More of Britain's publicly funded Earth sciences research should be relevant to the needs of people and policy-makers, according to a former leader of the country's natural environment research body.

Sir John Knill, who used to head the Natural Environment Research Council (NERC), told the annual meeting of the Geological Society last week that informal research showed the public had a high level of interest in the applied Earth sciences, such as climate change and natural hazards.

But whereas such topics are a high priority in NERC's directed research programmes, data on 'responsive mode' funding show that Earth scientists are more interested in more specialized fields.

"There is a mismatch here," he said. "We need to convince ourselves that public opinion matters."

In a keynote lecture, 'How we need to

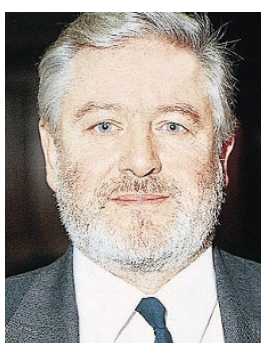

convince society that it needs geological research', Knill told his audience that by paying less attention to public interests, Earth scientists had lowered their stock in the eyes of policy-

Knill: Earth scientists should consult public. makers. He revealed that the Geological Society is one of the few learned bodies not being consulted in the second round of the government's Technology Foresight programme.

Knill said that if Earth scientists want to be heard in government, they need also to lobby civil servants. "What a minister writes or says is usually written by other people. We need to influence those 'other people."

\section{Japan set to inject funds into endocrine disrupter research}

[TOKYO] Research into the effects of endocrine disrupters, the man-made chemicals suspected of disrupting human reproductive functions, is about to expand in Japan. Such research is likely to receive a significant boost as part of the government's 16 trillion yen ( $\$ 121$ billion) economic stimulus package for the current fiscal year (which began on 1 April).

Plans to allocate $¥ 10$ billion towards setting up a endocrine disrupter research laboratory were announced by Japan's Liberal Democratic Party (LDP), the ruling party, last week. If approved by the parliament, this would become the largest national project on 'environment hormones', as the chemicals are known in Japan.

Details of the stimulus package are due to be announced by the Finance Ministry on 24 April. Although the issue of endocrine disrupters is not directly relevant to the government's economy-boosting measures, it is considered "an urgent matter that must be tackled as part of the national agenda", according to an LDP spokesman.

Widespread concern about the effects of 'environment hormones' was precipitated last year by the release of a report compiled by the Environment Agency. This listed 67 chemical compounds, such as dioxins, polychlorinated biphenyl compounds (PCBs) and organic tin compounds, which were suspected of mimicking naturally occurring sex hormones.

Although the details of endocrine disrupters' effects on the human reproductive system are still unknown, many scientists agree on the importance of increasing knowledge about the potential danger of man-made chemicals being dispersed into the environment.

"It is not easy to determine the effect of each chemical substance on mankind that has been released into the environment," says Taisei Nomura, a professor in embryology at Osaka University. "But, given their potential impact on human reproductive organs, it is essential that more research is carried out."

The new laboratory would be set up at the Environment Agency's National Institute for Environmental Studies, in Tsukuba. It would focus on methods to detect the presence of endocrine disrupters by analysing chemical compounds found in soil and water samples.

Meanwhile, the Science and Technology Agency intends to fund a separate three-year research programme on endocrine disrupters and other environmental pollutants, such as formaldehyde. This project, the cost of which is estimated to be more than $¥ 400$ million a year, will be carried out jointly by 30 national institutes and industry.
AsakoSaegusa 